\title{
Magnetic nanocomposite-system for the remediation of lead-contaminated urban surface
}

\author{
Ahsan Maqbool ${ }^{1}$, Hui Wang ${ }^{1}$, Muhammad Saeed ${ }^{2}$, and Aimen Hafeez ${ }^{3}$ \\ ${ }^{1}$ School of Environmental Sciences and Spatial Informatics, China University of Mining and \\ Technology, China \\ ${ }^{2}$ Department of Irrigation and Drainage, University of Agriculture, Pakistan \\ ${ }^{3}$ Department of Environmental Sciences, International Islamic University, Islamabad, Pakistan
}

\begin{abstract}
Lead pollution contributes $2 \%$ to environmental health and is found in air, dust, soil, and water. The presence of lead on the urban surface can put at risk human health and hinder sustainable urban development. The existing strategies are not feasible to remediate lead from the urban surface due to heavy infrastructure, long-term monitoring, and less space availability. Therefore, the magnetic nanocomposite-system is designed to remove lead from the urban surface regardless of contaminated sites within a short period of time and is immediately applicable. The magnetic nanocomposite is synthesized by hydrothermal treatment and has plenty of hydroxyl and carboxyl functional groups with mesoporous surfaces. The results showed that the leadremoval efficiency exceeded $97 \%$ even at a high concentration of $300 \mathrm{mg} / \mathrm{L} . \mathrm{pH}$ has no significant effect on the removal efficiency. Also, it has shown stability and removal efficiency over $96 \%$ even after five reuse cycles. The proposed mechanism for the implication and separation of the magnetic nanocomposite system for the in-situ remediation approach has also highlighted the various applicable sites.
\end{abstract}

\section{Introduction}

Lead is one of the most significant environmental health threats and can be found in the air, dust, soil, water, and as indoor and consumer goods [1]. Exceptionally high ecological and geochemical changes, mainly related to human activities, have covered the geochemical system of urban soils. Settlements occupy only about $5 \%$ of the land area, but virtually the entire population of the planet lives within them [2]. The main medium of lead deposing in cities is soil, the ecological and geochemical conditions of which in many respects determine the safety of citizens' life. According to the Environmental Performance Index, lead contributes $2 \%$ to the concentration of lead in the environment arising due to mining, extraction of minerals, and the processing of metals that pollute the soil. Lead is produced at the shooting ranges and, during military hostilities concentrates on berm areas in the vicinity of cities. [3]. Atmospheric lead, produced from gasoline and industrial emission [4], can be transported far away from the emission source, settled on the urban surface (green belts, roadside walks, playgrounds, parks, and commercial areas, and many others) 
and attached to soil particles. Road yellow paint has also been detected as a lead source on the settlement or urban topsoil and surface [5]. This lead settled on the urban surface can resuspend into the air, penetrate groundwater or accumulate in vegetation [6,7]. Bioaccumulation of lead in the food chain can cause risks to human health and damage plant organs [8]. Airborne lead content from anthropogenic activities (mining activities, processing industry, and coal fly ash) affects the composition, cytotoxicity, and genotoxicity of surrounding soils $[9,10]$. Plants have a high accumulation potential to uptake lead in urban areas [11], posing a risk to safe urban farming or kitchen gardening trends. Lead poisoning can produce mental retardation in children, neuropathies, lungs and skin cancer, and hypertension in adults [1]. Therefore, it is necessary to remediate leadcontaminated urban soil for the sustainability of environmental and public health.

Although the toxicity of lead is well documented, managing the exposure and mitigation of related risksis a worldwide challenge in a complex and flexible environmental system. Existing remediation strategies, such as soil washing, immobilization of metals, and reduction of bioavailability using a sorbent with large surface area(biochar, nanocoated composite, etc.), electrochemistry, and phytoremediation are intended for remote areas. Many comprehend the impact of the lack of an efficient chelating agent, mobilization of metals over the years, slow capture, lack of a separation mechanism for the sorbent, energy consumption, lengthy treatment, and monitoring time. Phytoremediation is an energyefficient method that reduces the bioavailability of lead, soil organic carbon, and nutrients in the soil. An approach to overcome pollution is under development. Physiochemical removal of lead would be appropriate using a sorbent as indicated in the literature [12-14], but these sorbents for wastewater, agricultural soil, and acid mine soil, do notseparate from the soil. Moreover, sorbent can accumulate via drinking water sources and food chains due to self-aggregation and have an eco-toxic impact on bacteria, mammalian cells, microarthropods, and other soil inhabitants [15]. Therefore, it lacks a regeneration mechanism, control over its movement, and separation mechanism in accordance with the requirements of the site on the urban surface.

In this study, a new functionalized magnetic nano carbon-coated $(\mathrm{MnC})$ composite was designed, synthesized, and used in a magnetic nano composite system to remediate leadcontaminated soil. It can be applied to every contaminated site, as mentioned above, with flexible needs regarding the lead settled on urban surface. Experimental studies are conducted in soil, since atmospheric $\mathrm{Pb}$ (II) is deposited on the topsoil on the urban surface. The effects of the use of a magnetic nanocomposite-system are also being identified in lead-contaminated sites with deposited dust around the world to mitigate their impact on urban surfaces. Besides, experimental lead-contaminated sites have been highlighted worldwide where a magnetic nanocomposite system could be applied consistent with observed removal efficiency.

\section{Materials and methods}

\subsection{Materials}

All chemical reagents of the analytical grade of the experiment were received without purification and purchased from Sigma-Aldrich. A local company in China provided magnetic ceramsite with an average particle size of $3 \mathrm{~mm}$ in diameter. Air-dried soil was sieved $(2 \mathrm{~mm})$, then spiked soil prepared for the required contamination in the soil treatment laboratory. For the experiment, deionized water was acquired from the university water treatment plant. 


\subsection{Synthesis of magnetic nanocomposite}

The magnetic nanocomposite was synthesized via hydrothermal treatment as discussed [14]. Raw magnetic ceramsite was soaked in $\mathrm{HCl}(3 \mathrm{M})$ aqueous solution under magnetic stirring with $160 \mathrm{rpm}$ at room temperature $\left(25^{\circ} \mathrm{C}\right)$ for 10 -hours. The resulting system was dried after washing and filtration with water, night-long at $60^{\circ} \mathrm{C}$. Afterward, $20 \mathrm{~g}$ of the resulting system was added into $200 \mathrm{~mL}$ of sucrose $(0.4 \mathrm{M})$ solution and stirred for half an hour. Then, the resulting system was put into an oven for 24 hours at $200^{\circ} \mathrm{C}$. Subsequently, after filtration, washing and drying overnight $\left(60^{\circ} \mathrm{C}\right)$, a magnetic expanded clay nanocarbon coating was obtained. Then the resulting system was transferred into a PEG aqueous solution with a ratio of $4: 1.5=\mathrm{W}_{\mathrm{n}} / \mathrm{W}_{\mathrm{PEG}}$ by weight and stirred for 1.5 hours at 300 $\mathrm{rpm}$. Finally, after filtration, washing and drying overnight $\left(60^{\circ} \mathrm{C}\right)$, a new material has obtained named $\mathrm{MnC}$.

\subsection{Characterization}

A scanning electron microscope (SEM) coupled with energy dispersive X-ray spectrometer (EDX, SU 8000, Japan) was used for morphological studies. Brunauer-Emmett-Teller (BET, ASAP2020, USA) was applied for studying physical characteristics in terms of pore size and surface area of the samples by adsorption-desorption of $\mathrm{N}_{2}$ gas at $77 \mathrm{~K}$. X-ray photoelectron spectroscopy (XPS, ESCALAB 250Xi, USA) was used to study chemical structure and interaction.

\subsection{Batch experiment}

A stock solution of lead was prepared using lead nitrate. For the adsorption isotherm, in 10 $\mathrm{g}$ of soil, $2 \mathrm{~g}$ of $\mathrm{MnC}$ is added with $20 \mathrm{~mL}$ of lead aqueous solution at $\mathrm{pH} 3.0$ with different initial concentrations of $20,50,100,200$, and $300 \mathrm{mg} / \mathrm{L}$, under $300 \mathrm{rpm}$ for 24 hours at $30^{\circ} \mathrm{C}$. Removal efficiency [RE, (\%)] of MnCwas estimated following Eq. (1):

$$
R E=\frac{\left(C_{i}-C_{r}\right)}{C_{i}} \times 100
$$

where $C_{i}$ and $C_{r}$ are the initial and final concentrations of HMs $(\mathrm{mg} / \mathrm{L})$.

For adsorption kinetics, in $10 \mathrm{~g}$ of soil, $1 \mathrm{~g}$ of $\mathrm{MnC}$ is added with $20 \mathrm{~mL}$ of lead solution at the initial concentration of $30 \mathrm{mg} / \mathrm{L}, \mathrm{pH} 6.0,30^{\circ} \mathrm{C}$ and stirring at $300 \mathrm{rpm}$, respectively. Afterward, the final concentration of lead is calculated to measure the removal efficiency at different periods of $\mathrm{MnC}$ by the above Eq. (1).

To assess adsorbent performance at different $\mathrm{pH}$ levels, in $5 \mathrm{~g}$ of soil, $1.25 \mathrm{~g}$ of $\mathrm{MnC}$ is added to $20 \mathrm{~mL}$ of lead solution at initial concentration $200 \mathrm{mg} / \mathrm{L}, \mathrm{pH} \mathrm{3,6}$, and 9, temperature $30^{\circ} \mathrm{C}$, and continuously stirred at $300 \mathrm{rpm}$ for 6 hours.

To access the effect of adsorbent dosage, in $5 \mathrm{~g}$ soil $0.5,1.25$, and $2 \mathrm{~g}$ of MnCare added to $20 \mathrm{~mL}$ of lead solution at initial concentration of $200 \mathrm{mg} / \mathrm{L}, \mathrm{pH} 6,30^{\circ} \mathrm{C}$ and stirred at 300 rpm for 6 hours.

A desorption experiment is carried out to investigate the regeneration or reusability of $\mathrm{MnC}$ after the adsorption stage. In $5 \mathrm{~g}$ of soil, $1 \mathrm{~g}$ of $\mathrm{MnC}$ is added to $20 \mathrm{~g}$ of lead solution at the initial concentration of $20 \mathrm{mg} / \mathrm{L}$ of $\mathrm{MnC}$, separated from the soil after 6 hours by an external magnet. Then, the used $\mathrm{MnC}$ was placed into $\mathrm{HCl}(0.5 \mathrm{M})$ solution for 6 hours for desorption. Afterward, $\mathrm{MnC}$ is collected, washed at room temperature, and used again. The mechanism of separation of $\mathrm{MnC}-\mathrm{Pb}$ from the contaminated soil after remediation by a 
magnetic set is shown in Fig. 1C. The desorption efficiency (DE) of $\mathrm{MnC}$ is determined using the following Eq. (2):

$$
D E=\frac{\left(C_{i}-C_{r}\right)}{C_{i}} \times 100
$$

\subsection{Characterization of soil samples}

After $\mathrm{Pb}$ (II) adsorption, $\mathrm{MnC}$ was removed from the slurry by an external magnetic system. The slurry was oven-dried overnight at $105^{\circ} \mathrm{C} .1 \mathrm{~g}$ of each soil sample was pretreated for acid digestion $\left(\mathrm{HCl}: \mathrm{HNO}_{3}\right.$ : $\left.\mathrm{HF}: \mathrm{HClO}_{4}, 3: 1: 3: 1\right)$ at $200^{\circ} \mathrm{C}$ in a Digiblock digestor LabTech, Inc. USA, under USEPA 3050 guidelines. After acid digestion, $40 \mathrm{~mL}$ of deionized water was added into the test tube with $1 \mathrm{~mL}$ of $\mathrm{HNO}_{3}$ for further analysis.

Herein, to determine the metal concentration in soil samples after acid digestion, inductively coupled plasma-mass spectrometry (ICP-MS, PerkinElmer Co., USA) was used. Multi-element stock solutions of 10, 20, 50, 100, $200 \mathrm{mg} \cdot \mathrm{kg}^{-1}$ concentration were prepared to calibrate and validate the ICP-MS. Blank samples were also prepared to trace the acids in soil via the acid digestion process. To minimize the error, standard solutions were run to know the precision and accuracy of ICP-MS after analyzing every ten samples.

A benchtop $\mathrm{pH}$ meter was used to measure the soil $\mathrm{pH}$ in the soil-water phase.
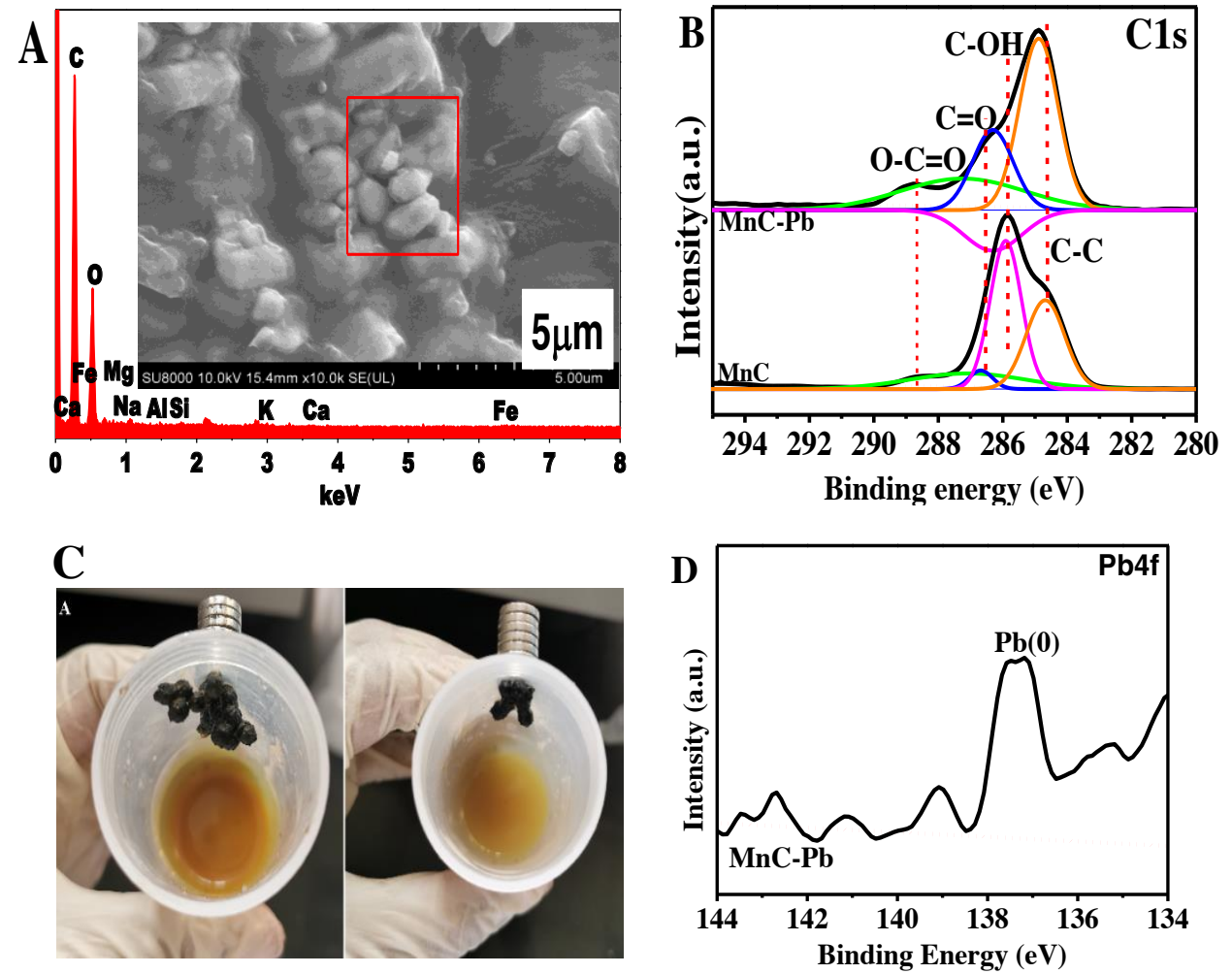

Fig. 1. A) EDX spectra and SEM of MnC, B) XPS spectrum of $\mathrm{MnC}$ before and after adsorption of lead at $\mathrm{C} 1 \mathrm{~s}$ peak after deconvolution, C) separation of $\mathrm{MnC}$ from the soil via external magnetic set, and D) XPS spectra of $\mathrm{MnC}$ after the removal of lead at binding energy peaks. 


\section{3 results and discussions}

\subsection{Physicochemical Characteristics}

SEM observes the morphology, topography, and composition of MnC. Magnetic ceramsite can have low adsorption capacity, and the formation of a nanocarbon coating, which could cause stability problems, has limited use due its thick layer and weak mechanical bonding [16]. PEG can be used to reinforce, restrain, and functionalize the sorbent to enhance the significance and capability of its functionality. Fig.1A displayed an even surface with the usual spherical shape after adaptation with PEG, signifying that PEG can increase the adhesion ability. EDX spectra revealed that $\mathrm{MnC}$ is composed of $\mathrm{Si}, \mathrm{Ca}, \mathrm{Na}, \mathrm{Al}, \mathrm{Fe}, \mathrm{K}$, and $\mathrm{Mg}$ (Fig.1A) with high mechanical strength. In MnC, the content of oxygen $(\mathrm{O})$ and carbon (C) indicates the accessibility of functional groups. The BET surface area of $\mathrm{MnC}$ is 0.7953 $\mathrm{m}^{2} / \mathrm{g}$, and the volume is $6.0897 \mathrm{~nm}^{3}$, respectively, indicating the micro-mesoporous surface. In the XPS spectrum, after deconvolution, the obtained peaks are affirmed to $\mathrm{C}-\mathrm{C}, \mathrm{C}-\mathrm{OH}$ (phenol or alcohol groups), $\mathrm{C}=\mathrm{O}$ (carbonyl groups), and $\mathrm{O}-\mathrm{C}=\mathrm{O}$ (carboxyl groups) in Fig. 1B (Garcia-Perez et al. 2019).
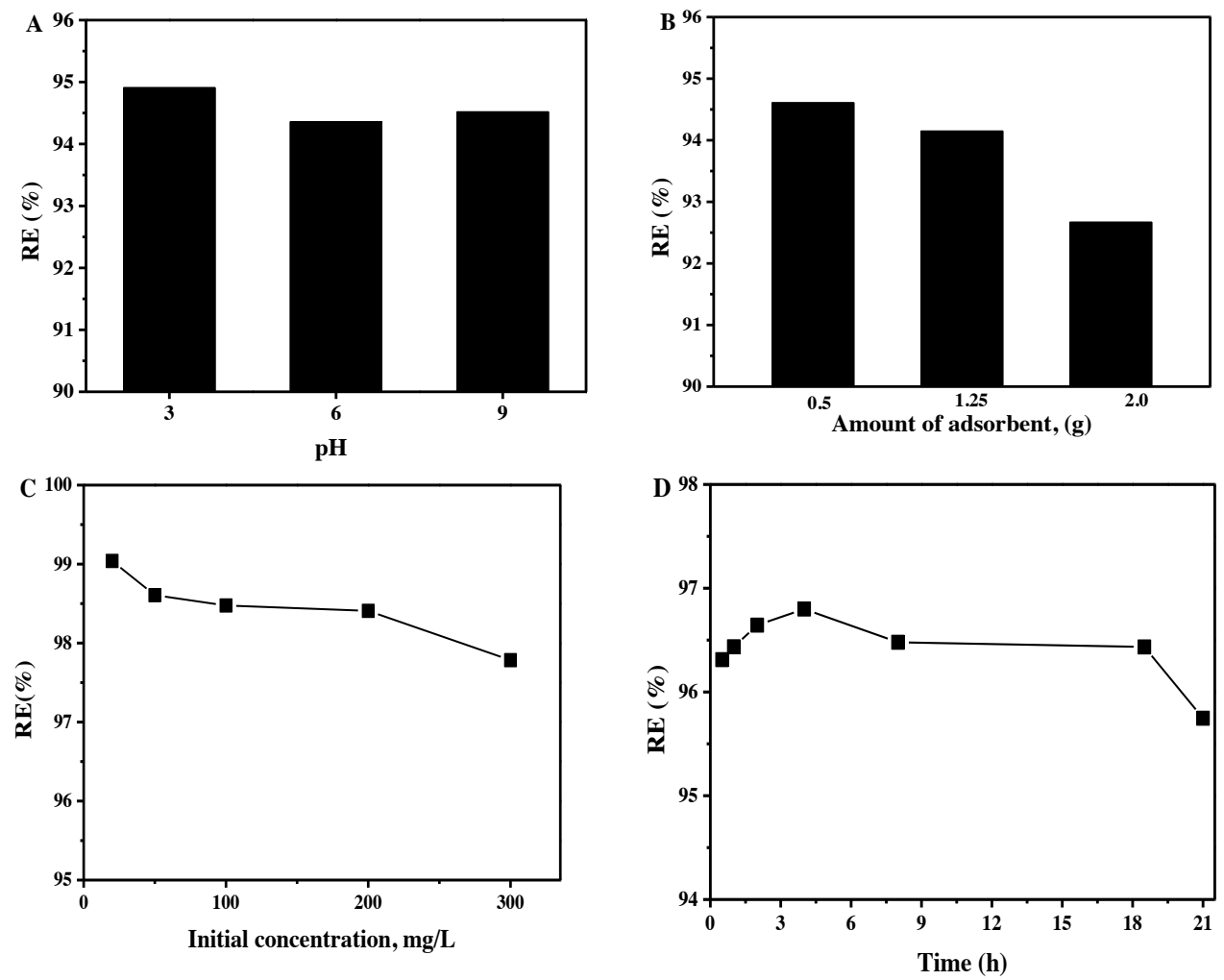

Fig. 2. A) effect of pH, B) effect of the amount of adsorbent, C) effect of the amount of initial concentration (C), and D) effect of time on removal efficiency of $\mathrm{MnC}$ for the lead from soil. 


\subsection{Removal Characteristics}

The removal efficiency of lead using MnC sorbent characteristics is presented in Fig. 2. The $\mathrm{pH}$ effect depicted that the removal performance of $\mathrm{MnC}$ for the lead was over $94 \%$ and remains the same at 3,6, and 9 (Fig. 2A), which shows that $\mathrm{pH}$ has no noticeable or dominant effect on the sorbent. At the same time, it was previously found that biochar can alter reclaimed soil properties [17]. The acidic $\mathrm{pH}$ promotes desorption of metal ions towards target anions from the soil surface through a protonation exchange mechanism or due to electrostatic attraction on the surface of sorbent $(\mathrm{MnC})$ [18]. Meanwhile, as the amount of sorbent increased from 0.5 to $2 \mathrm{~g}$, the removal efficiency decreased from 94.61 to $92.67 \%$ (Fig.2B). It revealed that the amount of adsorbent had a reciprocal or rebound effect on $\mathrm{Pb}$ (II) removal. However, $\mathrm{Wu}$ et al. studied that sorption of metal ions increases with an increase in the initial concentration of metal ions to the ratio of the ratio of the adsorbent in the soil [19]. An increased initial concentration leads to a decrease in $\mathrm{Pb}$ (II) removal efficiency, decreasing slightly from 99.17 to $97.78 \%$ (Fig. 2C). Even at a high initial concentration $(300 \mathrm{mg} / \mathrm{L})$ of lead, $\mathrm{MnC}$ has shown extremely high removal efficiency $(97.78 \%)$ in the soil.

In soil, when the time interval or $\mathrm{MnC}$ contact increased, the removal efficiency first increased (Fig. 2D) at 4-hour contact time, showing maximum removal efficiency (96.67 $\%$ ); this treatment time could reduce the nutrient loss in soil. However, with EDTA soil washing under asymmetrical alternating current electrochemistry, the nutrient loss was registered after 6 hours of treatment for lead removal [20]. Subsequently, the removal efficiency declines gradually, showing that the reaction-balanced stage was reached within 4-hour of $\mathrm{MnC}$ treatment time with lead in soil

The reusability and regeneration of $\mathrm{MnC}$ were assessed in five following sorption cycles. The sorption efficiency decreased by more than $96 \%$ in each $\mathrm{MnC}$ reuse cycle. The efficiency of lead sorption slightly declined after each cycle. The results showed that after adsorption of metal cations, $\mathrm{MnC}$ could be effectively regenerated by a fast process in $\mathrm{HCl}$ $(0.5 \mathrm{M})$. This efficiency of regeneration showed better results than the reported composite modified by carboxyl-functionalized and polypyrene adaption $[21,22]$.

\subsection{Removal Mechanism}

The chemical interaction for removing lead from soil was studied by XPS analysis on the $\mathrm{MnC}$ surface. The surface of $\mathrm{MnC}$ has an abundance of hydroxyl and carboxyl functional groups which alter their specific binding energy. Firm peaks of Pb4f in the XPS spectra (Fig.1D) revealed that $\mathrm{PbO}_{2}$ and $\mathrm{Pb}$-metal indicating coincide with metal hydroxides and a mixture of zero-valent state $[14,20]$. $\mathrm{C} 1$ s peaks (Fig. 1B) of $\mathrm{MnC}-\mathrm{Pb}$, referring to the sigma bond $(\mathrm{C}-\mathrm{C})$ formed by hybridization of each carbon atom, $\pi$-bond resulting from hybridization of $\operatorname{sp}^{3}(\mathrm{C}-\mathrm{O})$, and a single bond of carbon to oxygen. The double bond is more potent than the $\pi$-bond $(\mathrm{O}-\mathrm{C}=\mathrm{O})$ after treatment in lead-containing soil, which is likely to be reduced by $\mathrm{R}-\mathrm{OH}, \mathrm{R}-\mathrm{COOH}$, and oxidized [14]. These functional groups have a weak affinity towards protons. After protonation, stronger bonds will form into the -OH groups due to the difference in electronegatively. When lead is adsorbed, bonds are formed with the surface-adsorbate (chemisorption) due to electrostatic attraction and the combinationof the monolayer. During the experiment, an external magnetic kit was used to separate the $\mathrm{MnC}$ after the removal of lead from the soil (Fig.1C). 
Table 1. Level of lead in settled dust at various location across the world where MnC.

\begin{tabular}{llcl}
\hline Location & Sampling site & Pb level $\left(\mathrm{mg}_{\mathrm{kg}}{ }^{-1}\right)$ & Ref \\
\hline Hermosillo, Mexico & Desert settled dust $(\mathrm{n}=21)$ & $70.3(29.3-261.6)^{*}$ & {$[5]$} \\
Lahore, Pakistan & Industrial area $(\mathrm{n}=13)$ & $187(141-278)^{*}$ & {$[23]$} \\
Beijing, China & Playground settled dust soil & $27.48(12.28-$ & {$[24]$} \\
Murcia, Spain & $(\mathrm{n}=71)$ & $326.3)^{*}$ & {$[25]$} \\
Ostrava, Czech & Urban street dust $(\mathrm{n}=127)$ & 177 & {$[25]$} \\
Republic & Industrial area settled road dust & 58.5 & {$[26]$} \\
Toronto, Canada & In=16) & 86 & {$[27]$} \\
\hline
\end{tabular}

*mean value, minimum and maximum.

High removal efficiency at higher concentrations of metallic contaminants and reusability have shown the stability and potential of MnCto remove HMs from the urban surface with precipitated dust. Table 1 shows the lead content in the deposited dust at various sites, indicating that $\mathrm{MnC}$ can remove them, which is of great importance. $\mathrm{MnC}$ shows this efficient lead removal capacity, which can have a comprehensive range of impacts despite the acidic mine environment and saline soil, as $\mathrm{pH}$ has no significant effect. $\mathrm{MnC}$ can be spread randomly, water can be applied to the contaminated area, and the sorbent can be separated after two hours using an external magnetic system (Fig.3). The magnetic lawnmower needs to be developed to separate $\mathrm{MnC}$ for reuse from the urban surface.

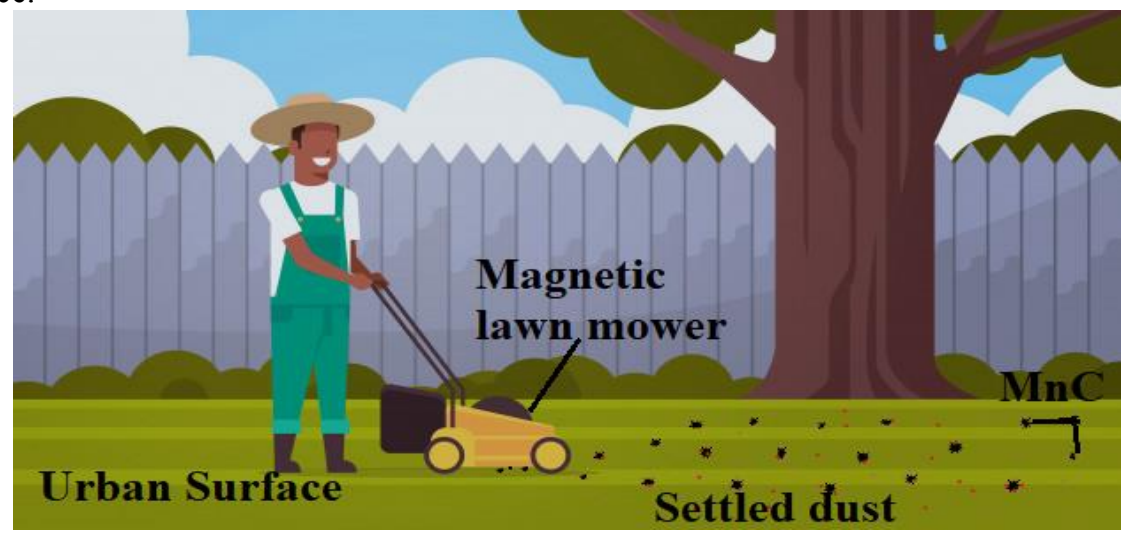

Fig. 3. Proposed implication and separation mechanism of $\mathrm{MnC}$ for the removal of lead from the urban surface.

\section{Conclusions}

A mesoporous magnetic carbon nanocoated composite is synthesized by hydrothermal treatment. Physicochemical characterization has revealed that composite has hydroxyls and carboxylic functional bases on the surface and becomes abundant through further treating of polyethylene glycol. At a high initial concentration $(300 \mathrm{mg} / \mathrm{L})$ of lead in the soil, the composite has shown $97.78 \%$ removal efficiency. Meanwhile, at the equilibrium stage, the contact time of the sorbent with the lead content in the soilwas set at 4 hours. Experiments on regeneration and reusability further enhance the significance of composite after confirming a removal efficiency of $96 \%$ during the $5^{\text {th }}$ cycle. The conceptual removal mechanism available through XPS analysis means the lead has been oxidized and reduced to zerovalence from the surface-divalent composite in the soil. Magnetic nanocomposite 
has a promising development in terms of applying as proposed by the remediation mechanism to an in-situ approach.

The magnetic material can be reused many times, and the collection system itself only needs to be slightly modified and fixed in the lawnmower. Another advantage is that chemicals and materials are not very expensive and were used to synthesize the magnetic composite and readily available to local supply chain stores. Since the collection process is combined with lawn trimming, there is no additional labor cost of the collection. Therefore, the remediation approach and recovery method will be economically viable.

\section{References}

1. Z.A. Wendling, J.W. Emerson, D.C. Esty, M.A. Levy, A. de Sherbinin, 2018 Environmental Performance Index (Yale University, New Haven, 2018).

2. V. Alekseenko, A. Alekseenko, The abundances of chemical elements in urban soils. Journal of Geochemical Exploration, 147: 245-249 (2014).

3. A. Rodríguez-Seijo, M.C. Alfaya, M.L. Andrade, F.A. Vega, Copper, Chromium, Nickel, Lead and Zinc Levels and Pollution Degree in Firing Range Soils. Land Degradation \& Development, 27(7): 1721-1730 (2016).

4. M.T. Sarwar, Z.H. Hui, A. Maqbool, Causes and control measures of urban air pollution in china. Environment\&Ecosystem Science, 3(1): 35-36 (2019).

5. D., Meza-Figueroa, B., González-Grijalva, F., Romero, J., Ruiz, M.,Pedroza-Montero, C.I. Del, Rivero, M. Acosta Elías, L. Ochoa-Landin, S. Navarro-Espinoza, Source apportionment and environmental fate of lead chromates in atmospheric dust in arid environments. Science of The Total Environment, 630: 1596-1607 (2018).

6. V. Kuznetsov, D. Petrov, Assessing the Environmental Condition of Minor Rivers in Urban Areas. Journal of Ecological Engineering, 18: 110-114 (2017).

7. V. Matveeva, T. Lytaeva, A. Danilov, Application of steel-smelting slags as material for reclamation of degraded lands. Journal of Ecological Engineering, 19: 97-103 (2018).

8. A. Maqbool, X. Xiao, W. Hui, Z. Bian, M.W. Akram, Bioassessment of heavy metals in wheat crop from Soil and dust in a coal mining area. Pollution, 5(2): 323-337 (2019)

9. Medunic, G., Ahel, M., Božičević Mihalić, I., Srček, V., Kopjar, N., Fiket, Ž., Bituh, T., Mikac, I., Toxic airborne S, PAH, and trace element legacy of the superhigh-organicsulphur Raša coal combustion: Cytotoxicity and genotoxicity assessment of soil and ash. Science of The Total Environment, 566: 306-319 (2016).

10. Ž. Fiket, G. Medunic, Ž. Vidaković-Cifrek, P. Jezidžić, P. Cvjetko, Effect of coal mining activities and related industry on composition, cytotoxicity and genotoxicity of surrounding soils. Environmental Science and Pollution Research, 27 (2019).

11. Q., Zhang, R., Yu, S., Fu, Z.,Wu, H.Y.H., Chen, H., Liu, Spatial heterogeneity of heavy metal contamination in soils and plants in Hefei, China. Scientific Reports, 9(1): 1049. (2019).

12. I.M., El-Naggar, S.A., Ahmed, N., Shehata, E.S., Sheneshen, M., Fathy, A.,Shehata, A novel approach for the removal of lead (II) ion from wastewater using Kaolinite/Smectite natural composite adsorbent. Applied Water Science, 9(1) (2019).

13. G. Medunić, P.S., Singh, A.L., Singh, A., Rai, S., Rai, M.K., Jaiswal, Z.,Obrenović, Z., J neš, M.,Petković, Use of Bacteria and Synthetic Zeolites in Remediation of Soil and Water Polluted with Superhigh-Organic Sulfur Raša Coal (Raša Bay, North Adriatic, 
Croatia). Water, 11: 1419 (2019).

14. A. Maqbool, W. Hui, X. Xiao, A. Khaliq, M.T. Sarwar, Removal of heavy metals from urban soil using functionalized carbon-coated composite. International Journal of Environmental Science and Technology, 17(12): 4787-4802 (2020).

15.X. Bai, S. Zhao, L. Duo, Impacts of carbon nanomaterials on the diversity of microarthropods in turfgrass soil. Scientific Reports 7(1): 1779 (2017).

16. L. Zhou, G. Zhang, M. Wang, D. Wang, D. Cai, Z. Wu, Efficient removal of hexavalent chromium from water and soil using magnetic ceramsite coated by functionalized nano carbon spheres. Chemical Engineering Journal, 334: 400-409 (2018).

17. Zh. Cai, T. Zheng, A. Maqbool, W. Hui, Z. Bian, Does biochar promote reclaimed soil qualities? Land Reclamation in Ecological Fragile Areas. CRC Press, Taylor \& Francis Group, 6000 Broken Sound Parkway NW, Suite 300, Boca Raton, FL 33487-2742, 579581 (2017).

18. E. Ghasemi, A. Heydari, M. Sillanpää, Superparamagnetic Fe3O4@EDTA nanoparticles as an efficient adsorbent for simultaneous removal of $\mathrm{Ag}(\mathrm{I}), \mathrm{Hg}(\mathrm{II})$, $\mathrm{Mn}(\mathrm{II}), \mathrm{Zn}(\mathrm{II}), \mathrm{Pb}(\mathrm{II})$ and $\mathrm{Cd}(\mathrm{II})$ from water and soil environmental samples. Microchemical Journal, 131: 51-56 (2017).

19. H. Wu, Q. Wen, L. Hu, M. Gong, Effect of Adsorbate Concentration to Adsorbent Dosage Ratio on the Sorption of Heavy Metals on Soils. Journal of Environmental Engineering, 144(2): 04017094 (2018).

20. J. Xu, C. Liu, P. Hsu, J. Zhao, T. Wu, J. Tang, K. Liu, Y. Cui, Remediation of heavy metal contaminated soil by asymmetrical alternating current electrochemistry. Nature Communications, 10(1): 2440 (2019).

21. D.Wang, G. Zhang, Z. Dai, L. Zhou, P. Bian, K. Zheng, Z. Wu, D. Cai, Sandwich-like Nanosystem for Simultaneous Removal of Cr(VI) and Cd(II) from Water and Soil. ACS Applied Materials \& Interfaces, 10(21): 18316-18326 (2018).

22. S. Sahu, P. Kar, N. Bishoyi, L. Mallik, R.K. Patel, Synthesis of Polypyrrole-Modified Layered Double Hydroxides for Efficient Removal of Cr(VI). J. Chem. Eng. Data, 64, 4357-4368 (2019).

23. A. Rehman, G. Liu, B. Yousaf, M. Zia-ur-Rehman, M.U. Ali, M.S. Rashid, M.R. Farooq, Z. Javed, Characterizing pollution indices and children health risk assessment of potentially toxic metal(oid)s in school dust of Lahore, Pakistan. Ecotoxicology and Environmental Safety, 190: 110059 (2020).

24. Y. Jin, D. O'Connor, Y.S. Ok, D.C.W. Tsang, A. Liu, D. Hou, Assessment of sources of heavy metals in soil and dust at children's playgrounds in Beijing using GIS and multivariate statistical analysis. Environment International, 124: 320-328 (2019).

25. P. Marín Sanleandro, A. Sánchez Navarro, E. Díaz-Pereira, F. Bautista Zuñiga, M. Romero Muñoz, Delgado M. Iniesta, Assessment of Heavy Metals and Color as Indicators of Contamination in Street Dust of a City in SE Spain: Influence of Traffic Intensity and Sampling Location. Sustainability, 10: 4105 (2018).

26. K. Čabanová, O. Motyka, P. Peikertová, J. Seidlerová, I. Olivková, J. Kukutschová, Settled Dust from Urban and Suburban Roads in an Industrial City Area: Location and Seasonal Differences in Metal Content. Journal of Nanoscience and Nanotechnology 19(5): 3035-3040 (2019).

27. A.Al Hejami, M. Davis, D. Prete, J. Lu, S. Wang, Heavy metals in indoor settled dusts in Toronto, Canada. Science of The Total Environment,703 (2020). 